\title{
Histomorphological observation of the small intestine of Red Sokoto Goat: a review
}

\begin{abstract}
In the past year there have been many advances in the area of absorption and assimilation of food material in relation to histological function of the small intestine in identifying and diagnosing pathology and therapy. In preparation for this review, many books and research papers were assessed. The focus is on presenting clinically useful information for the practicing veterinary gastroenterologist
\end{abstract}

Keywords: histological observation, small intestine, Red Sokoto Goat
Volume 6 Issue 3 - 2019

\author{
Bello A, Danmaigoro A \\ Department of Veterinary Anatomy, Usmanu Danfodiyo \\ University, Nigeria
}

Correspondence: Bello A, Department of Veterinary Anatomy, Usmanu Danfodiyo University, Sokoto, Nigeria, Tel +234(0)8039687589, Email abccrcfge28@gmail.com

Received: February 12, 2019 | Published: May 16, 2019

\section{Introduction}

Goats and sheep are among small ruminant having four chambered stomach (Rumen, Reticulum, Omasum and Abomasum) as with other mammals' ruminant. ${ }^{1}$ They are characterized as even-toed ungulates. The histology of the wall of the small intestine differs somewhat in the duodenum, jejunum, and ileum, but the changes occur gradually from one end of the intestine to the other. The duodenal portion indicates the presence of submucosal mucous glands (Brunner's glands). ${ }^{2}$ The small intestine of most domestic species is quite similar in function and histology. ${ }^{3}$ The small intestine is divided into three distinct segments from oral to aboral; duodenum, jejunum and ileum. ${ }^{4}$ The structural and functional differences in specie regions of the small intestine impart differential functional capabilities to these segments.

The wall of the goat small intestine was composed of the typical layers found in mammals: lamina epithelialis mucosa, lamina propria, lamina muscularis mucosa, tunica mucosa, tunica muscularis and tunica serosa. ${ }^{5}$ The mucosal epithelium in all three small intestine segments was columnar .Goblets cells were scattered among the columnar epithelial cells. ${ }^{6}$

The digestive functions require voluminous amount of digestive enzymes in addition to a copious supply of mucus to protect the lining cells from mechanical injury and irritating compounds. The enzymes originates from the columnar absorptive cells and the pancreas the enzymes produced by the columnar absorptive cells are membrane bound at the micro villi luminal surface, while those produce by the pancreas mix freely with the luminal contents.?

The Mucus is produced by sub mucosal glands in the small intestine and by goblet cells which intermingled with the columnar absorptive cells throughout the entire intestine. ${ }^{8}$

The tunica mucosa was composed of 3 layers: the lamina mucosa lined by a simple columnar epithelium), lamina propria, and lamina muscularis. ${ }^{1}$ The inner surface of the small intestine is covered with finger-like projections referred to as villi, which increase the surface area available to the absorption of nutrients from the gut content. ${ }^{1}$ By increasing the surface area of the small intestine, villi increase the chance of a food particle encountering a digestive enzyme and being absorbed across the epithelium and into the blood stream. ${ }^{5}$

The villi are mucosal protections and are the most characteristic features of the small intestine ${ }^{9}$ these are finger like in the dog and horse but broader and leaf like in many species. ${ }^{2}$

The crypts of Lieberkühn were tortuous, tubular glands with a wide lumen and occurred in the lamina propria throughout the small intestine ${ }^{10}$ in goats. The crypts were more extensive in cranial part of the duodenum. In jejunum the crypts of Lieberkühn were long and extensive. The crypts of Lieberkühn were dilated and branched in the ileum. ${ }^{4}$ The lamina epithelialis of the small intestine was lined mainly by simple columnar cells. Goblet cells and enterochromaffin cells were there. Paneth cells were present at the base of intestinal glands in all three segments of the small intestine. ${ }^{11}$

The columnar absorptive cells have a void nuclei situated near the cell base have prominent microvilli that form a straighter border. ${ }^{12}$

Goblet cells are dispersed among the columnar absorptive cells, the numbers of goblet cells are decreased at the tips of the villi however, the density of the goblet cell is two to three times greater in the ileum than in the duodenum. ${ }^{8}$

The goblet cells were dispersed among the columnar cells of villi as well as crypts of Lieberkühn in all three regions of the small intestine. The number of the goblet cells was less in the cranial part of the duodenum, and then increased in caudal portion of duodenum and became progressively greater in the jejunum and ileum. The goblet cells of villi were smaller in size than those of the crypts. ${ }^{13}$

The simple tubular intestinal glands (crypts of lieberkuhn) are lined by a variety of cell types, the principal cell types of intestinal glands are the undifferentiated columnar cell. ${ }^{2}$ These cells multiply differentiate and migrate into the villus giving rise to the columnar absorptive cells and the goblet cells. ${ }^{14}$ The intestinal villi are contiguous with gland located at the base of villi, the crypt of lieberkkuhn or intestinal crypts. ${ }^{15}$ The lamina propria forms the cores of villi and surrounds the intestinal glands; it is compose of loose connective tissue with a prominent reticular fibre framework. ${ }^{16}$ The lamina propria form the core of villi and surrounds the intestinal glands, it is compose of primarily of loose collagenous tissue, but contains a number of important structure and cells. ${ }^{17}$

The villous lamina propria is rich in both capillaries and lymphatic that help transport nutrient absorbed by enterocyte across the luminal surface. ${ }^{18}$ Within the extensive fibre network are blood lymph vessels, 
leukocytes fibrocytes, smooth muscles cells, plasma cells and mast cell and Globule leukocytes are found most in the intestinal mucosa of most domestic species. ${ }^{11}$

The lamina muscularis is composed of inner circular and outer longitudinal layers of smooth muscle that tend to be thin and in complete. ${ }^{4}$ The lamina muscularis mucosa contained only circularly arranged layer of smooth muscle bundles for most of the small intestine and separated the lamina propria from the tunica sub mucosa. The lamina muscularis mucosa was interrupted at some places in the region of duodenum with Brunner's glands and in ileum by nodules of Peyer's patches. ${ }^{5}$ Bello et al. ${ }^{3}$ have described that the lamina muscularis mucosa was discontinuous and even absent in the area of duodenal glands. The lamina muscular may vary with the species the individual animal and the region.

Tela submucosa is a layer of connective tissue that is denser than that of the lamina propria. Tubuloalveolar submucosal glands (Brunner's glands) confined to the submucosa of the duodenum, especially its initial part, also secrete a protective mucus..$^{13}$ The submucosal glands are mucous in dogs and ruminant in which the mucous secretary product of these glands lubricate the surface epithelium and provide protection from the acidic gastric chyme. ${ }^{19}$ The glands are present in all domestic mammals but their distribution varies with the species. ${ }^{1}$

Isolated lymphatic nodules are present in the submucosa throughout the small intestine. Large aggregated lymphatic nodules Payer's Patches occur in all three segments of the small intestine but they are usually considered to be more characteristic of the ileum, which can be located grossly. ${ }^{8}$

Tunica muscular consist of inner circular and outer longitudinal smooth muscle layer, in which the two layer are nearly equal in thickness, the connective tissue between the two muscle layer contain the myenteric plexus. ${ }^{19}$

The tunica serosa was the thin, outer most layer comprised of scant amount conjunctive tissue cover by mesothelium. ${ }^{16}$ Tunica serosa covers the entire small intestine, it consists of a layer of loose connective tissue covered by mesothlium. ${ }^{6}$ Distinguishing microscopic anatomic feature of the duodenum, jejunum and ileum are detailed below. (Figure 1)

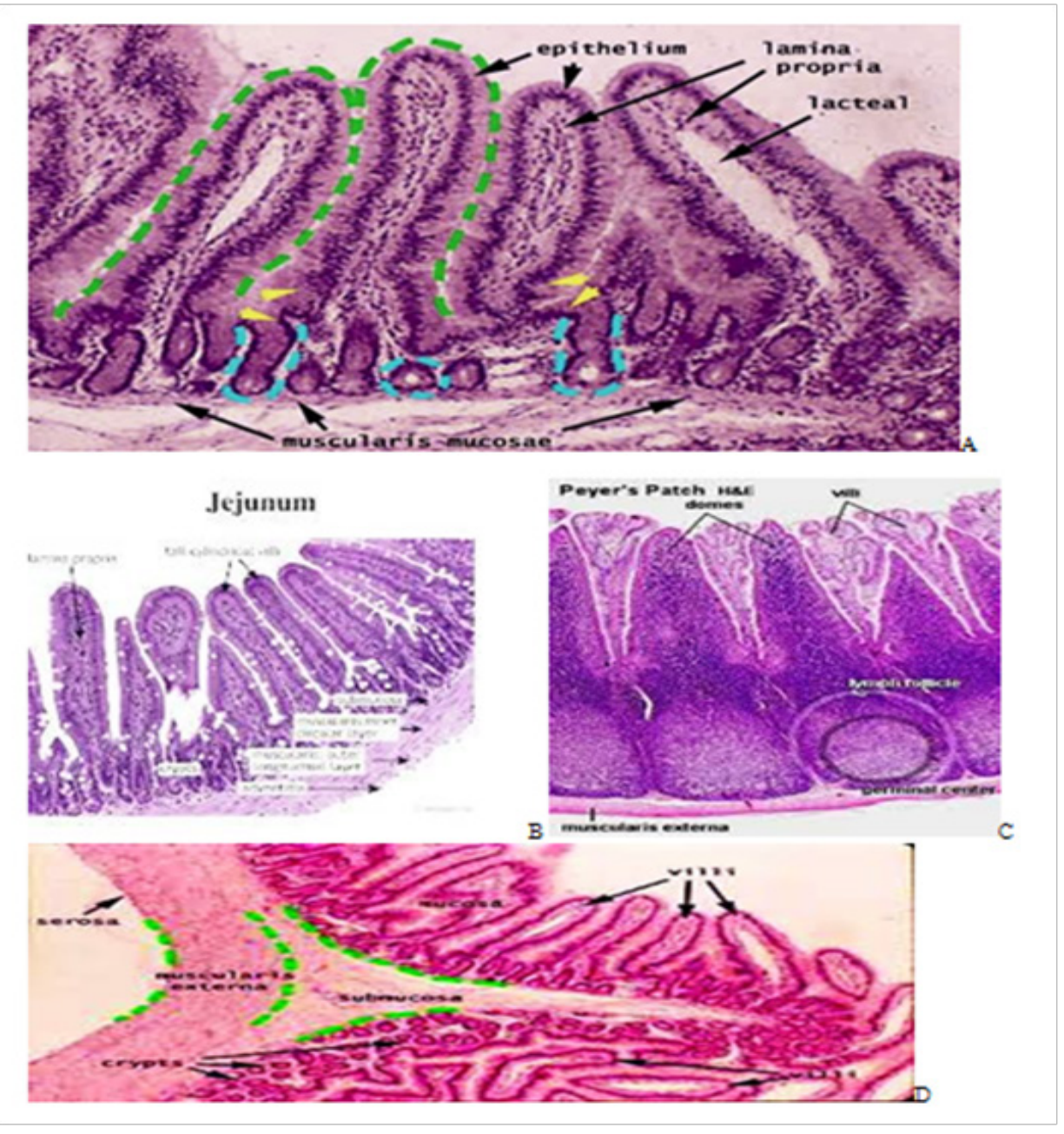

Figure I Photomicrograph of small intestine tissue A (duodenum), B (jejunum), C (ileum) and D (duodenum), showing the differences of various segment of the small intestine $\mathrm{H}$ and $\mathrm{E} \times 200$. 


\section{Duodenum}

The wall of duodenum and jejunum was made up of tunica mucosa, submucosa, muscular and serosa. ${ }^{1}$ The tunica mucosa of the region was studded with villi of different shapes and size which were lined by simple columnar epithelium having few goblet cells. ${ }^{7}$ The villi of cranial part of duodenum were short, stout with broad base; there were also flat leaves like villi with pointed to blunt apexes. Gradually these became tall, slender and finger like as progressed toward the jejunum where these attained maximum height. ${ }^{6}$ The columnar cells of epithelium of duodenum had elongated oral and round basophilic nuclei present toward the base. ${ }^{17}$

The lamina propria mucosa was dense having reticular, collagen and elastic fibre along with connective tissue cells like fibroblast lymphocytes and fine blood capillaries. ${ }^{13}$ The lymphoid tissue aggregate was observed these were scattered between the crypts of lieberkhun and villi as observed in sheep. ${ }^{6}$ The intestinal glands were extensive and compactly arranged tubule-acinar glands which were lined with simple columnar cells goblet cells few paneth cells and enterochromaffin cells. ${ }^{12}$

These were slightly decreased towards the caudal part of duodenum as reported in sheep. ${ }^{7}$ The nuclei of these glands were round to oval and were present towards the basal portion showing condensation of chromatin materials into smaller basophilic clumps especially towards the nuclear membrane as observed in sheep. ${ }^{2}$

The enterochromaffin cells were found to be maximum in duodenum region especially in its cranial segment part and these cells decreased toward the jejunum as also reported in buffalo. ${ }^{2,5}$ Their number was more towards the basal part of the crypts which was in agreement to the earlier finding in sheep. ${ }^{2}$ The paneth cells were present towards the base of the crypts and their number was gradually increased toward the jejunum as reported in sheep. ${ }^{17}$

The lamina muscular mucosa varied in thickness and a few places it was interrupted due to exclusion of submucosal glands in duodenum and invasion of lymphoid nodules into the propria towards caudal part of the jejunum as observed in sheep. ${ }^{3}$

The submucosa was formed by more irregular connective tissue and connective tissue cells; fine blood capillaries along with elastic, collagen and reticular fibre. ${ }^{9}$ It was mainly occupied by sub mucosal or Brunner's glands which were more in number toward cranial part then caudal part of the duodenum as in observed in sheep. ${ }^{15}$ The follicle associated epithelium (FAE) was present between absorptive epithelial cells and devoid of goblet cells as reported in sheep. ${ }^{6}$

Tunica muscularis was moderately thick in both the segment. It was consisted of an inner circular and outer longitudinal layer of smooth muscle fibre. ${ }^{10}$ Kumar et al. ${ }^{17}$ reported similar findings in sheep and buffalo respectively.

Tunica serosa formed by loose irregular connective tissue had isolated collagen, elastic and reticular fibre along with varying amount of fatty tissue and few blood capillaries flat mesothelial cell layer was present. ${ }^{17}$

\section{Jejunum}

The wall of the jejunum was comprised of tunica mucosa tunica submucosa, tunica muscular and tunica serosa. ${ }^{5}$ The tunica mucosa had villi of different shapes and size lined by simple columnar epithelium having few goblet cells. ${ }^{18}$ Similar observations have been reported in buffalo ${ }^{15}$ and other domestic animal. ${ }^{1}$ The villi were pointed and elongated in its anterior portion while these were broad and blunt shaped towards the ileum. Kumar et al. ${ }^{17}$ reported leaf shaped or tongue shaped villi in buffalo calves and also reported that some villi were pointed at their tips. The villi of dog and cat have been reported to be much longer. ${ }^{20}$ However, in pigs these were finger like long and slender in shape. ${ }^{2}$

In the cranial part of the jejunum the villi were elongated with pointed ends but they were elongated with blunt apical ends towards the caudal part of the jejunum. ${ }^{3}$ The number of goblets cells varied from few to moderate from cranial to caudal end of the jejunum. ${ }^{21}$ The nuclei had 1-2 nucleoli which were centric or eccentric in position. The cytoplasm was slightly eosinophillic and granular. A few lymphocytes were observed between the columnar cells. Barnwal \& Yadava $^{22}$ reported oval or round nuclei situated at the base of the cells in buffalo calve.

The goblet cells of epithelium showed a strong reaction for acid mucopolysaccharides and a moderates PAS positive reaction for neutral mucopolysaccharides. ${ }^{20}$ However, Bello et al. ${ }^{3}$ reported that the luminal border of columnar epithelium of jejunum of Gaddi goat showed decreased to moderate reaction with PAS. The villi and the basement membrane of the epithelium showed moderate to weak reaction with Alcian blue stain throughout the intestine in Gaddi goat. ${ }^{2}$ In mammal the striated border of columnar cells were PAS positive in small intestine ${ }^{13}$ along with positive reaction to alcian blue. Weak PAS and Alcian blue reaction by the columnar absorptive cells have been reported in goat, sheep and cattle. ${ }^{1}$

The lamina propria had loose irregular connective tissue along with reticular, collagen and elastic fibres. In addition, there were few lymphoid cells throughout the jejunum length and lymphoid aggregate were also observed. ${ }^{12}$ In contrast, Barnwal \& Yadava ${ }^{22}$ reported large number of lymphocytes in lamina propria in buffalo.

The Intestinal glands or crypts of lieberkuhn were simple, branched, coiled tubular glands lined with simple Cuboidal to low columnar epithelium. ${ }^{13}$ In buffalo glands were made up of undifferentiated columnar cells along with very far to nil goblet cells. ${ }^{1}$ In Gaddi goat, the crypts showed moderate reaction in the supranuclear zone of the epithelium with PAS and mild reaction with alcian blue stain. ${ }^{1}$

The lamina muscular mucosa varied in thickness and was made up of smooth muscle fibres. ${ }^{8}$ At few place it was interrupted due to the presence of large amount of lymphoid tissue and extension of crypts of lieberkuhn. ${ }_{5}$ In buffalo, it was made up of continues layer of smooth muscle fibres arranged in two rows. ${ }^{9}$ The lamina muscularis mucosae formed a thin continuous liner circular and outer longitudinal smooth muscle layer in jejunum of pig $^{1}$ and other domestic animals. ${ }^{8}$

The tunica submucosa was formed by loose irregular, connective tissue having connective tissue cells fine blood capillaries along with elastic, collagen and reticular fibre. ${ }^{20}$ Payer's patches were present towards the caudal end of the jejunum and at Jejuno-ileal junction as reported in buffalo. ${ }^{6}$ Tunica muscular was constituted by inner circular and outer longitudinal layers of smooth muscles in between these layers there were blood vessels, nerves bundle and at places 
mesenteric plexus was also observed. ${ }^{20}$ Tunica serosa was comprised of loose irregular connective tissue having collagen, elastic and reticular fibre along with varying amount of fatty tissue. ${ }^{9}$ Few blood capillaries and Flat mesothelial cells were also present similar findings have also been reported earlier in domesticated animals.

\section{Ileum}

The ileal mucosa contains large number of organized lymphoid tissue (lymphoid follicles) termed payer's patches. The payer's patches serves as both a primary and secondary lymphoid organs payer's patches are critical components of the GALT. ${ }^{3}$ The various regions of the small intestine in the domestic mammals are not clearly defined microscopically as they are in human beings. For examples the submucosal glands do not extends the full length of the duodenum in sheep, goats and carnivores whereas in horses, cattle and pigs, these glands extend into the Jejunum. ${ }^{1}$ Likewise, the aggregated lymphatic's nodules (Payer's patches) often considered an identifying features of the Ileum, may be seen anywhere along the small intestine of domestic mammals. ${ }^{4}$

Because the length of the villi varies with physiologic activities and with species, it is not a reliable characteristic for the identification of the various segments. ${ }^{19}$

Branches of the celiac and cranial mesenteries arteries, causing in the mesoduodenum and mesentery (Mesojejunum and Mausoleum), penetrate the tunica muscular is along the line of mesenteries attachment. These arteries give off branches to supply the tunica muscular and continue into the submucosa, where they form a submucosal arterial plexus. ${ }^{3}$ The plexus give rise to short arteriole which supply capillary beds around the lamina muscular and intestinal (Mucosal) glands and long arteriole which extend to the tips of the villi. In the villi, the simple arteriole supplies a capillary network and continues to the tips of the villus, where it is continues with a venue forming an arteriole venular loop. Venules from the villi and the periglandular capillary bed combine to form a submucosal venous plexus. This plexus give rise to veins that transverse the tunica muscular parallel to the arteriole supply and drain into the portal vein. ${ }^{13}$

\section{Intestinal glands}

Histologically, an intestinal gland (also crypt of lieberkn or intestinal crypt) is a glands found in the intestinal epithelium lining of the small intestine and large intestine (Colon). ${ }^{5}$ The glands and intestinal villi are covered by epithelium which contains multiple types of cells Enterocyptes (absorbing water and electrolytes), goblet cells (secreting mucus) entero-endocrine cells (secreting hormones), Cup bell left cell and at the base of the glands, paneth cells (secreting antimicrobial peptides) and stem cell. These cells are not all present in the colon. ${ }^{3}$

\section{Blood supply and innervations}

Blood supply to the intestinal tract is mainly provided by the cranial and caudal mesenteries arteries. However, the initial part of the duodenums is supplied through the hepatic branch of the celiac artery and the caudal part of the rectum by rectal branches of the internal pudendal artery. The cranial mesenteries artery supplies the bulk of the small intestine, the ileocaecocolic junction region. ${ }^{17}$

The veins are broadly comparable and join to form the cranial and caudal mesenteries vein two of the main portal radicals. The splenic vein is the third of the portal vein. ${ }^{19}$

The lymphatic drainage of the small intestine in particular is copious since some of the products of digestion are absorbed by this route when these products include fat, the lymph is milky and the intestinal lymphatic vessels (lacteals) are unusually conspicuous. The flow is directed toward certain nodes through which the lymph percolates before joining the cistern chyll. The dilated origin of the thoracic ducts, the most important lymphatic vessels. ${ }^{10}$

The intestine receives both sympathetic and parasympathetic nerves. The sympathetic pathways lead through the celiac cranial mesenteries and caudal mesenteries ganglia with the post ganglion fibre enmeshing the relevant arteries the parasympathetic pathways involves both vagal and pelvic nerves. ${ }^{15}$

\section{Conclusion}

The review has been able to provide reasonable documentary facts to support the knowledge of digestion, absorption and assimilation in the production of small ruminant animals in Nigeria. The production of goats will provide meat, milk, skin and wool for the farmers and a good source of revenue to the state government. In view of the economic advantage associated with goat production coupled with the availability of local feedstuffs in the zone, the scientist and producers should be provided with facilities for commercial production of small ruminant animals. The local breeds of goat should be upgraded by experts in the zone for optimum productivity.

\section{Acknowledgements}

None.

\section{Conflicts of interest}

The authors declare there is no conflict of interest.

\section{References}

1. Banks WJ. Applied Veterinary Histology. 3rd ed. USA: Mosby Year Book; 1992:327-351.

2. Hassan A, Ciroma, Hart R, et al. Case studies for a Workshop-Research on Crop-animal Systems. India: Catie/Winrock International; 1982.

3. Rey B, Lebbie SHB, Reynolds L. Body weight measurement relationship in Nigeria Red Sokoto Goats. In: Proceedings 1st Biennial Conference African shall Ruminant Research Network Nairobi Kenya ILCA. 1992:491497.

4. Adedeji OS, Gbadamosi AJ. Relationship of scrotal circumference of Age, Body weight and the right and left scrotal length in Red Sokoto (Maradi) goats. Proceeding of 26th Annual Nigerian Society of Animal Production (NSAP) Conference 21-25, Ilorin, Nigeria. 1999:305-309.

5. Douglas CE. Goats, sheep and cows could challenge dogs for title of 'man's best friend'. The Conversation. 2016.

6. Hirst, Kris K. The History of the Domestication of Goats. 2008.

7. Akpa GN, Duru S, Amos TT. Influence of strain and sex on estimation of within-age group body weight of Nigerian Maradi goats from linear body measurements. Tropical Agriculture (Trinidad). 1998;75:462-467.

8. Gizaw S. Estimation of body weight from linear body measurement and the influences of body condition and age on accuracy of weight estimation in Ethiopian Harro sheep. Nairobi, Kenya ILRI, SRNET News. 1995:5-9. 
9. Bello A, Onyeanusi BI, Sonfada ML, et al. A biometric study of the digestive tract of one-humped camel (Camelus dromedarius) fetuses. Scientific Journal of Zoology. 2012;1(1):11-16.

10. Dutta AK, Sahu MK, Gangadharan SK, et al. Distinguishing Crohn's disease from intestinal tuberculosis- a prospective study. Trop Gastroenterol. 2011;32(3):204-209.

11. Ndlova LR, Simela L. Effect of season of birth and sex of kid on the production performance of live weaned single born kids in small holder East African goat flock in North East Zimbabwe. Small Ruminant Research. 1996;22(1):1-6.

12. Taylor RE, Field TG. Scientific farm animal production: an introduction to animal science. 6th ed. USA: Prentice-Hall Upper Saddle River; 1999:321-324.

13. Gajbhonya PU, Johar KS. Predicting body weight on the basis of body measurement in Magra sheep. Indian Journal of Animal Science. 1985;55(7):604-606.

14. Noran AM, Mukherjee TK. Physical traits versus the buck's reproductive abilities. Australian Journal of Animal Science. 1997;10(2):245-250.

15. Zachariah SK. Adult necrotizing enterocolitis and non occlusive mesenteric ischemia. J Emerg Trauma Shock. 2011;4(3):430-432.
16. Iqbal T, Khan A, Iqbal A, et al. Obstruction due to intestinal tuberculosis strictureplasty versus resection anastomosis. Pak J Surg. 2008;24(3):177178.

17. Kumar B, Bratte L, Arijeniwa A, et al. Age and Body Weight and their relationship with testicular and horn development in Yankasa West African Dwarf crossbred rams. Journal of Applied Animal Research. 1999;15(2):201-206

18. Navaneethan U, Cherian JV, Prabhu R, et al. Distinguishing tuberculosis and crohn's disease in developing countries: how certain can you be of the diagnosis? Saudi J Gastroenterol. 2009;15(2):142-144.

19. Pulimood A, Ramakrishna B, Kurian G, et al. Endoscopic mucosal biopsies are useful in distinguishing granulomatous colitis due to Crohn's disease from tuberculosis. Gut. 1999;45(4):537-541.

20. Krishnamurthy V, Basavaraj V, Sunila, et al. Neuromuscular and vascular hamartoma of the small bowel: a rare cause of intestinal obstruction. J Lab Physicians. 2010;2(2):109-110.

21.http://www.surgwiki.com/wiki/Radiation_injuries_to_the_small_and large_bowel

22. Barnwal, Yadava. Cytogenetics in the dog and cat. J Small Anim Pract. $2003 ; 7: 575-592$ 